\title{
A Study of Intestinal Absorption of Bicyclol in Rats: Active Efflux Transport and Metabolism as Causes of its Poor Bioavailability
}

\author{
Wei Tan, Hui Chen, Jing Zhao, Jinping Hu, Yan Li
}

Department of New Drug Development, Institute of Materia Medica, Peking Union Medical College, Chinese Academy of Medical Sciences, Beijing, 100050, People's republic of China.

Received January 4, 2008; Revised July 1, 2008; Accepted August 25, 2008; Published August 31, 2008

ABSTRACT - Purpose. To determine the possible mechanism of poor bioavailability of bicyclol, and clarify the respective contribution of P- glycoprotein (P-gp) and Cytochrome 3A (CYP3A). Methods. Rat in situ single-pass intestinal perfusion and Caco-2 cell monolayer model with selective inhibitors of CYP3A and P-gp were employed. Results. In rat intestinal perfusion, bicyclol $(50 \mu \mathrm{M})$ appearance in mesenteric blood $\left(\mathrm{P}_{\text {blood }}\right)$ was increased 3, 12 and 16-fold after addition of inhibitors of P-gp (LSN335984), CYP3A (troleandomycin, TAO) or P-gp and CYP3A (Cyclosporin A, CsA), respectively, whereas permeability of midazolam (CYP3A substrate only) was unchanged after addition of LSN335984 and increased 5 fold after addition of TAO. Moreover, the cumulative amount of bicyclol in mesenteric blood was increased at concentration range $10-100 \mu \mathrm{M}$ of bicyclol in perfusate. The basolateral to apical permeability value of bicyclol in Caco-2 monolayer was significantly deceased by LSN335984 and CsA. Conclusions. The poor bioavailability of bicyclol is mostly due to P-gp mediated efflux and metabolism by CYP3A in intestine, with CYP3A making more contribution than P-gp.

\section{INTRODUCTION}

Bicyclol(4,4'-dimethoxy-5,6,5',6'-Bis(dimethylen e-dioxy)-2-hydroxymethyl-2'-methoxy-carbonylbi phenyl; Fig 1), a new synthetic anti-hepatitis drug, has been used in patients with chronic hepatitis B to improve liver function and partially inhibit hepatitis B virus replication in China (1).A variety of pharmacological studies showed that bicyclol markedly protected against experimental liver injury induced by certain toxins such as acetaminophen, concanavalin A, carbon tetrachloride, lipopolysaccharide, D-galactosamine and dimethylnitrosamine (2-5). Pharmacokinetic data indicated the poor bioavailability (9\%) of bicyclol in rats. In addition, an earlier study demonstrated that bicyclol was mainly metabolized by CYP $3 \mathrm{~A}$ in rat and human liver microsomes (6).<smiles>COc1cc(CO)c(-c2c(C(=O)O)cc(OC)c3c2OCO3)c2c1OCO2</smiles>

Figure 1. Chemical structures of bicyclol.

Correspondence Author: Yan Li; Department of New Drug Development, Institute of Materia Medica; Beijing, People's republic of China. E-mail:yanli@imm.ac.cn 
Biotransformation of drugs on passage across the enterocyte during oral absorption has been shown to significantly contribute to the first-pass effect of a number of compounds (7). It has been further suggested that the intestinal metabolism may be increased if the compound is also a substrate of an apically localized efflux transporter, such as P-gp (8-10). In small intestine, P-gp has been localized to the apical membrane of intestinal epithelial cells, consistent with its role in effluxing compounds back into the intestinal lumen (11). CYP3A4 is the major oxidative drug-metabolizing enzyme found in the intestine and is localized in the endoplasmic reticulum of enterocytes $(12,13)$. The extensive overlap in substrate specificities, tissue, localization, and coinducibility of P-gp and CYP3A4 has led to the hypothesis that these two proteins work together to protect the body from absorption of harmful xenobiotics, including drugs (14). Therefore, it is more likely that the co-effect of P-gp and CYP3A4 attenuates the absorption of compounds and leads to low bioavailability.

In the present study, in situ single-pass perfusion and Caco-2 models were used to determine the possible mechanism of the low bioavailability of bicyclol.

\section{MATERIALS AND METHODS}

\section{Chemicals}

Bicyclol and dimethyl dicarboxylate biphenyl (DDB) were kindly provided by Beijing Union Pharmaceutical Plant (Purity >99\%). LSN335984 was a gift of Eli Lilly Co, USA. TAO was purchased from Sigma-Aldrich chemical (St. Louis, MO, USA). CsA was a product of Norvatis Co.(Beijing,China). Acetonitril (HPLC grade) was obtained from Fisher (Fisher Scientific, United Kingdom). Caco-2 cell were obtained from Cell Center, Institute of Basic Medical Research. Minimum Essential medium, fetal bovine $\quad$ serum, $\quad 0.05 \% \quad$ trypsin ethylenediaminetetraacetic acid, penicillin-streptomycin were obtained from Gibco Co. Other chemicals were of analytical grade and obtained from the local market.

\section{Cell culture conditions}

Caco-2 cells used in the study were from passage 40-55. Briefly, Caco-2 cells were routinely cultured in $25 \mathrm{~cm}^{2}$ culture flasks in MEM (Gibco -Invitrogen Corporation) containing $1 \%$ penicillin-streptomycin, $\quad 2 \% \quad$ stabilized L-glutamine, $10 \%$ fetal bovine serum (FBS) and $1 \%$ nonessential amino acid at $37^{\circ} \mathrm{C}$ in an atmosphere of $95 \% \mathrm{O}_{2}$ and $5 \% \mathrm{CO}_{2}$. The cells were harvested at approximately $95 \%$ confluence and seeded at a density of $4.8 \times 10^{4}$ cells per Millicell ${ }^{\circledR}-\mathrm{PCF}$ (effective area $0.6 \mathrm{~cm}^{2}$, Millipore Corp, Carrigtwohill, Ireland). The transepithelial electrical resistance values of Caco-2 cell monolayers were measured, and only monolayers with transepithelial electrical resistance values higher than $420 \mathrm{ohm} \bullet \mathrm{cm}^{2}$ were used (15).

\section{Transport experiments}

Caco-2 cells (cultured for 21 days ) were rinsed for three times with HBSS and equilibrated at $37^{\circ} \mathrm{C}$ for one hour before transport experiment $(16,17)$.Subsequently, $40 \mu 1$ of HBSS containing bicyclol $(50 \mu \mathrm{M})$ was applied in the apical or basolateral side, respectively. A $50 \mu 1$ of aliquot was taken from the receiver side at different time intervals (30,60, 90, 120, 180, and $240 \mathrm{~min}$ ) and an equal volume of blank HBSS was immediately supplemented to maintain a constant volume.

\section{Inhibition studies}

To examine the influence of LSN335984 and CsA on the transport of bicyclol, CsA $(10 \mu \mathrm{M})$ and LSN335984 $(2 \mu \mathrm{M})$ were loaded into both sides of 
monolayer, simultaneously or 30 minutes before addition of bicyclol $(50 \mu \mathrm{M})$. Samples $(50 \mu 1$ each) were taken at different time intervals $(30,60,90$, 120,180 , and $240 \mathrm{~min}$ ) from the receiver side and the same volume of solution was supplemented after each sampling.

\section{Animals}

Male Sprague-Dawley rats $(280-350 \mathrm{~g})$ were obtained from the Animal Center of Chinese Academy of Medical Sciences. The animals were maintained on a 12-h light/dark cycle at the IMM Animal Care Facility and acclimatized for at least 3 days before the study. Rats were fasted overnight with free access to water and were anesthetized with $10 \%$ chloral hydrate at a dose of $350 \mathrm{mg} / \mathrm{kg}$ by intraperitoneal injection. All animals were kept at $37^{\circ} \mathrm{C}$ during the surgery and throughout in situ intestinal perfusion. Fresh heparinized donor blood $(13 \mathrm{U} / \mathrm{ml})$ was collected from donor rats immediately before surgery by cardiac puncture (18). All animal experiments were in compliance with the guidelines of China for animal care, which was conformed to the internationally accepted principles in the care and use of experimental animals.

\section{Surgical procedures}

The surgical procedures used in single-pass rat jejunum experiment were similar to those described elsewhere, with slight modifications (19). Briefly, the rat was heparinized $(90 \mathrm{U} / \mathrm{kg})$ via right jugular cannula ten minutes before mesenteric cannulation and the infusion rate of donor blood was $0.4 \mathrm{ml} / \mathrm{min}$ based on the outlet rate of mesenteric vein. An approximately 7 to $15 \mathrm{~cm}$ long segment of jejunum was chosen based on the mesenteric vein to be cannulated, and perfusate was infused into the intestinal segment at $0.3 \mathrm{~mL} / \mathrm{min}$.

\section{Single-pass intestinal perfusion}

The perfusate (Hank's balanced salt solution) with $\mathrm{pH}$ adjusted to 7.4 at $37^{\circ} \mathrm{C}$ was prepared. Phenol Red $(50 \mu \mathrm{M})$ was added to serve as a nonabsorbable marker for water flux. The perfusion buffer with bicyclol $(10-100 \mu \mathrm{M})$ or midazolam $(50 \mu \mathrm{M})$ in the absence or presence of $5 \mu \mathrm{M}$ LSN335984, $20 \mu \mathrm{M}$ TAO or $10 \mu \mathrm{M}$ CsA was infused into the jejunum individually. The blood from mesenteric vein and perfusate were collected at five minutes interval. The plasma separated by centrifugation and perfusate were immediately frozen at $-80^{\circ} \mathrm{C}$ until analysis.

\section{Sample preparation}

A $50 \mu 1$ of aliquots from Caco-2 cell culture or $40 \mu 1$ of perfusate was mixed with $70 \mu$ of acetonitrile and $10 \mu \mathrm{l}$ of DDB $(10 \mu \mathrm{g} / \mathrm{ml})$ was added as internal standard. After centrifugation at $12,000 \mathrm{rpm}$ for $5 \mathrm{~min}$ twice, $20 \mu 1$ or $1 \mu 1$ of each sample was taken for LC or LC-MS analysis, respectively.

Plasma sample $(150 \mu l)$ with $10 \mu 1$ of DDB $(5 \mu \mathrm{g} / \mathrm{ml})$ was mixed with $1 \mathrm{~mL}$ of dichloromethane. A $2 \mu 1$ of extraction was used for LC/MS determination. For the analysis of midazolam, perfusate sample $(40 \mu 1)$ at each time point was mixed with $10 \mu \mathrm{l}$ of omeprazole $(25 \mu \mathrm{g} / \mathrm{ml})$ as internal standard, and then mixed with $70 \mu 1$ of acetonitrile. After centrifugating at $12,000 \mathrm{rpm}$ for $5 \mathrm{~min}$ twice, $2 \mu 1$ of extraction was analyzed by HPLC. Plasma sample $(150 \mu 1)$ with $10 \mu 1$ of acetaminophen $(20 \mu \mathrm{g} / \mathrm{ml})$ served as internal standard was mixed with $1 \mathrm{ml}$ of diethyl ether, and then extracted with the above method.

\section{LC/MS analysis of bicyclol and midazolam}

Bicyclol and midazolam in plasma and perfusate were analyzed by LC/MSD Trap XCT mass spectrometer equipped with a series 1100 HPLC 
system consisting of a quaternary pump, automatic solvent degasser, autosampler and an automatic thermostatic column compartment. Analysis of bicyclol was performed as follows: Briefly, the sample was loaded onto the analytical column (Agilent C18 column, $2.1 \times 100 \mathrm{~mm}, 3.5$ $\mu \mathrm{m})$. The mobile phase consisted of water and methanol $(45: 55, \mathrm{v} / \mathrm{v})$, the column temperature was maintained at $30^{\circ} \mathrm{C}$, the flow rate was 0.2 $\mathrm{ml} / \mathrm{min}$, and the total run time was $9 \mathrm{~min}$. Using selective ion monitoring, signals for $[\mathrm{M}+\mathrm{Na}]^{+}$ ions of bicyclol $(\mathrm{m} / \mathrm{z} 413)$, and the internal standard DDB $(\mathrm{m} / \mathrm{z} 441)$ were obtained. The lower limit of quantitation was $3.3 \mathrm{ng} / \mathrm{ml}$ in rat plasma and intra- and inter-day accuracy ranged from $102-107 \%$ and $102-110 \%$, respectively. The absolute recovery values of bicyclol at plasma concentrations of $6.7,66.7$ and 333.3 $\mathrm{ng} / \mathrm{ml}$ were $85.3 \pm 4.9,94.6 \pm 5.9$ and $94.6 \pm 2.6 \%$, respectively.

Midazolam in plasma was analyzed with the same system. The mobile phase was consisted of water and methanol $(30: 70, \mathrm{v} / \mathrm{v})$ containing ammonium acetate $(5 \mathrm{mM})$. Using selective ion monitoring, signals for $[\mathrm{M}+\mathrm{H}]^{+}$ions of midazolam $(\mathrm{m} / \mathrm{z} 326)$ and the internal standard acetaminophen (m/z 152) were obtained.

An HPLC method was used for the analysis of bicyclol in Caco-2 cell culture: system Agilent 1100 controlled by Chemstation with a G1314A absorbance detector, Aichrom Bond-AQ C18 column $(4.6 \times 250 \mathrm{~mm}, 5 \mu \mathrm{m})$. The mobile phase for bicyclol analysis was water and methanol $(29: 71, \mathrm{v} / \mathrm{v})$ for bicyclol or water and methanol $(35: 65, \mathrm{v} / \mathrm{v})$ for midazolam.

\section{Data Analysis}

The permeability coefficient $\left(\mathrm{P}_{\mathrm{app}}\right)$ of bicyclol in Caco-2 cell was calculated as previously described (20). The concentrations obtained from the perfusate were corrected by the changes in water flux at each time interval using (Eq. 1):

$$
\text { Conc }_{\text {corrected }}=\text { Conc }_{\text {measured }} \times \frac{[\text { phenol red }]_{\text {in }}}{[\text { phenol red }]_{\text {out }}}
$$

The permeability of bicyclol and midazolam across rat intestine was calculated based on the appearance of drug in blood ( $\left.\mathrm{P}_{\text {blood }}\right)$ using the following equations (19):

$$
\mathrm{P}_{\text {blood }}=\frac{\frac{\Delta \mathrm{M}_{\mathrm{B}}}{\Delta \mathrm{t}}}{2 \pi \mathrm{r}<\mathrm{C}>}
$$

Where $r$ is the radius of the perfused intestinal lumen, $l$ is the length of the segment, $\Delta \mathrm{M}_{\mathrm{B}} / \Delta \mathrm{t}$ is the rate of drug appearance in mesenteric blood and $<\mathrm{C}>$ is the logarithmic mean concentration of drug in lumen.

Statistically significant difference between two groups was evaluated by Student's $t$ test. The prior level of significance was set at $\mathrm{p}<0.05$.

\section{RESULTS}

\section{Caco-2 cell monolayer model studies}

The absorptive $\mathrm{P}_{\text {app }}$ of bicyclol in Caco- 2 cell was $1.6 \pm 0.3 \times 10^{-5} \mathrm{~cm} / \mathrm{s}$, which was comparable to that from well-absorbed compounds (21). The basolateral to apical/ apical to basolateral (B-A/A-B) transport ratio of bicyclol was 1.94, indicating a significant efflux transport existing in Caco-2 cell. LSN335984 and CsA, the selective inhibitors of P-gp, were used to further determine how each inhibitor affected the transepithelial transport of bicyclol. As a result, the transport ratios of bicyclol were decreased to 1.00 and 1.19 , respectively, after addition of LSN335984 or CsA (Table 1). 


\section{Absorption and metabolism of bicyclol}

The profiles of bicyclol $(50 \mu \mathrm{M})$ appearance in mesenteric vein in the absence or presence of inhibitors of P-gp (LSN335984), CYP3A (TAO) or co-inhibitor of P-gp and CYP3A (CsA) are shown in Figure 2, and the relevant data are presented in Table 2. $\mathrm{P}_{\text {blood }}$ of bicyclol at a concentration of $50 \mu \mathrm{M}$ was $0.04 \pm 0.01 \times 10^{-4} \mathrm{~cm} / \mathrm{s}$ and increased to $0.20 \pm 0.06 \times 10^{-4} \mathrm{~cm} / \mathrm{s}$, $0.55 \pm 0.18 \times 10^{-4} \mathrm{~cm} / \mathrm{s}$ and $0.69 \pm 0.39 \times 10^{-4} \mathrm{~cm} / \mathrm{s}$ in the presence of LSN335984, TAO or CsA, respectively (Table 2). Therefore, the appearance of bicyclol in mesenteric blood $\left(\mathrm{P}_{\text {blood }}\right)$ was increased by 3 -fold in the presence of LSN335984, and elevated more significantly with TAO or CsA (Table 2 and Fig. 2). The data suggested that the co-effect of P-gp and CYP3A was significantly limiting the absorption of bicyclol across the intestine. Table 2 also presents the $\mathrm{P}_{\text {blood }}$ and cumulative amount in blood data as a function of the perfusion concentration. When the concentration was increased from $10 \mu \mathrm{M}$ to 50 $\mu \mathrm{M}$, there was a nonlinear increase $(50 \%)$ in the appearance of the cumulative amount of bicyclol in mesenteric blood, indicating that P-gp was effectively pumping the drug back into the intestinal lumen and limiting the drug absorption. However, when the bicyclol concentration was further increased to $100 \mu \mathrm{M}$, the unchanged amount of bicyclol in mesenteric blood was increased by 8.8 fold, suggesting that there might be a saturation of intestinal efflux and/or metabolism of bicyclol at the highest dose (Table 2, Fig.3).

\section{Absorption and metabolism of midazolam}

Midazolam, a CYP3A substrate not transported by P-gp, was used as a negative control in the present study. The $\mathrm{P}_{\text {blood }}$ of midazolam at steady state was $0.05 \pm 0.03 \times 10^{-4} \mathrm{~cm} / \mathrm{s}$ and unchanged by addition of LSN335984 $\left(0.06 \pm 0.03 \times 10^{-4} \mathrm{~cm} / \mathrm{s}\right)$. However, it was significantly increased by 5 fold by addition of TAO (Table 3).

\section{DISSCUSION}

This is a comprehensive study that employed both in vivo and in vitro models to further characterize the absorption and metabolism properties of bicyclol. The single-pass rat intestinal perfusion model with mesenteric blood sampling provided an isolated in vivo system to study the respective role of intestinal efflux transporter-P-gp and drug metabolizing enzyme-CYP3A (22).On the other hand, Caco-2 cell model was used to study the transport of bicyclol in vitro.

Table 1. Effects of LSN33598 and CsA on the transepithelial transport of bicyclol.

\begin{tabular}{llll} 
Condition & $\mathrm{A} \rightarrow \mathrm{B}\left(\times 10^{-5} \mathrm{~cm} / \mathrm{s}\right)$ & $\mathrm{B} \rightarrow \mathrm{A}\left(\times 10^{-5} \mathrm{~cm} / \mathrm{s}\right)$ & $(\mathrm{B} \rightarrow \mathrm{A}) /(\mathrm{A} \rightarrow \mathrm{B})$ Ratio \\
\hline $50 \mu \mathrm{M}$ (control) & $1.6 \pm 0.3$ & $3.3 \pm 1.0$ & $1.94 \pm 0.03$ \\
$50 \mu \mathrm{M}+$ LSN335984 & $1.5 \pm 0.1$ & $1.5 \pm 0.1^{*}$ & $1.00 \pm 0.05^{*}$ \\
$50 \mu \mathrm{M}+\mathrm{CsA}$ & $2.1 \pm 0.2$ & $2.4 \pm 0.3$ & $1.19 \pm 0.13^{*}$ \\
\hline
\end{tabular}

The AP-to-BL and BL-to-AP transport of bicyclol $(50 \mu M)$ across Caco-2 cell monolayers in the absence (control) or presence of $2 \mu \mathrm{M} L S N 335984$ (P-gp inhibitor) or 10 $\mu \mathrm{M} \mathrm{CsA} \mathrm{(CYP3A} \mathrm{and} \mathrm{P-gp}$ inhibitor) was examined. Data are expressed as mean $\pm S D$, and $n=3$. The statistically significant difference is between control and other experimental group. ${ }^{*} P<0.05$. 
Data from Caco-2 cell and rat intestinal perfusion suggested that bicyclol is a well absorbed compound comparable to other well-absorbed markers (21).However, the high permeability did not lead to high-level of bicyclol in the mesenteric blood (23), indicating that p-gp mediated efflux and drug metabolizing enzyme may both contribute to the poor bioavailability of bicyclol.

It was found that the permeability of bicyclol $\left(\mathrm{P}_{\text {app A-B }}=1.6 \pm 0.3 \times 10^{-5} \mathrm{~cm} / \mathrm{s}\right)$ in Caco-2 cell was similar to those of well-absorbed compounds such as propranolol $\left(1.13 \times 10^{-5} \mathrm{~cm} / \mathrm{s}\right)$, and testosterone $\left(3.3 \times 10^{-5} \mathrm{~cm} / \mathrm{s}\right)(24)$. The result from rat perfusion was consistent with in vitro study (25).

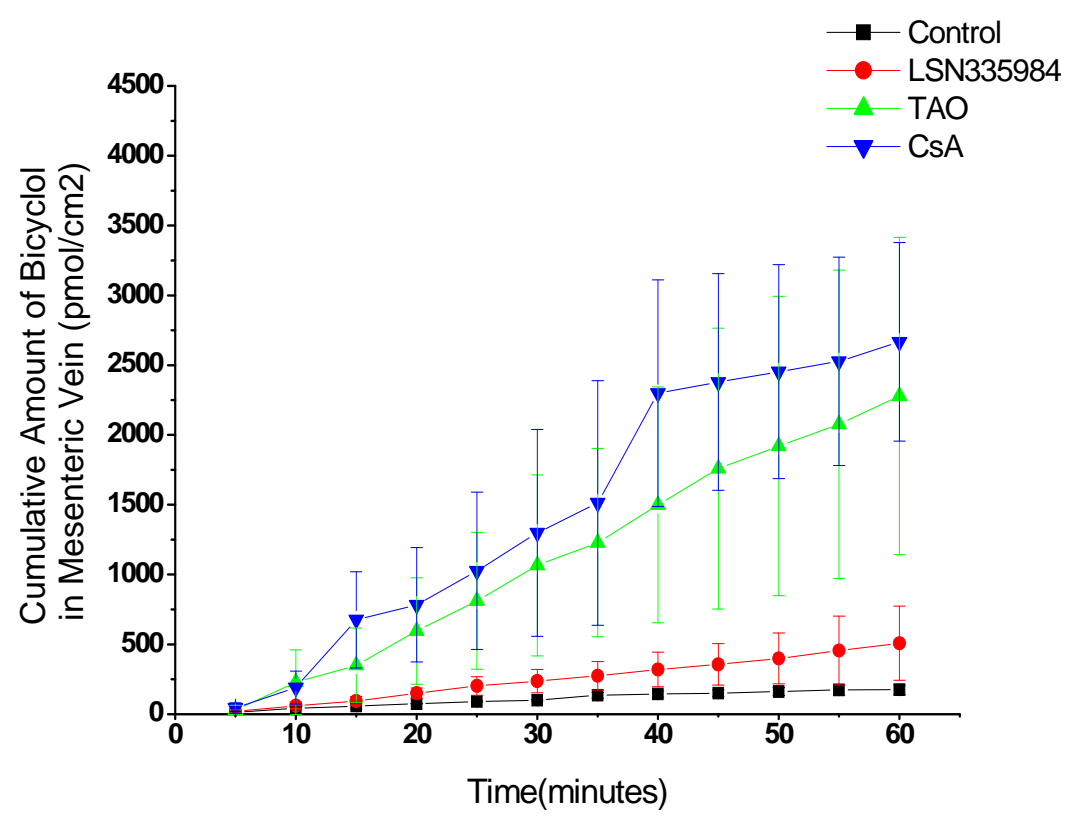

Figure 2. Cumulative amount of bicyclol appearing in mesenteric vein in the absence (control) or presence of LSN335984 (P-gp inhibitor), TAO (CYP3A inhibitor) or CsA (CYP3A and P-gp inhibitor) in rat jejunum perfusion study $(n=3-5)$. The concentration of bicyclol in the perfusate is $50 \mu \mathrm{M}$. Data are expressed as mean \pm SD.

Table 2. Permeabilities and cumulative amount of bicyclol in mesenteric vein across rat jejunum.

\begin{tabular}{ccc} 
Condition & $\begin{array}{c}\mathrm{P}_{\text {blood }} \times 10^{-4} \\
(\mathrm{~cm} / \mathrm{s})\end{array}$ & $\begin{array}{c}\text { Cumulative amount of drug in plasma } \\
(\mathrm{pmol} / \mathrm{cm} 2)\end{array}$ \\
\hline $10 \mu \mathrm{M}$ & $0.06 \pm 0.01$ & $103 \pm 60$ \\
$50 \mu \mathrm{M}$ & $0.04 \pm 0.01$ & $158 \pm 34$ \\
$100 \mu \mathrm{M}$ & $0.37 \pm 0.28$ & $1547 \pm 858^{* *}$ \\
$50 \mu \mathrm{M}+5 \mu \mathrm{M} \mathrm{LSN} 335984$ & $0.20 \pm 0.06^{* *}$ & $508 \pm 265^{* *}$ \\
$50 \mu \mathrm{M}+20 \mu \mathrm{M}$ TAO & $0.55 \pm 0.18^{* *}$ & $2000 \pm 934^{* *}$ \\
$50 \mu \mathrm{M}+10 \mu \mathrm{M}$ CsA & $0.69 \pm 0.39^{*}$ & $2110 \pm 843^{* *}$ \\
\hline
\end{tabular}

Bicyclol (10, 50,100 $\mu \mathrm{M})$ and bicyclol $(50 \mu \mathrm{M})$ in the presence of $5 \mu \mathrm{M}$ LSN335984 (P-gp inhibitor), 20 $\mu M$ TAO (CYP3A inhibitor) or 10 $\mu$ M CsA (CYP3A and P-gp inhibitor) were examined (n=3-5). Data are expressed as mean $\pm S D$. The statistically significant difference is between bicyclol (50 $\mu M)$ and other experimental group. ${ }^{*} P<0.05,{ }^{*} * P<0.01$. 


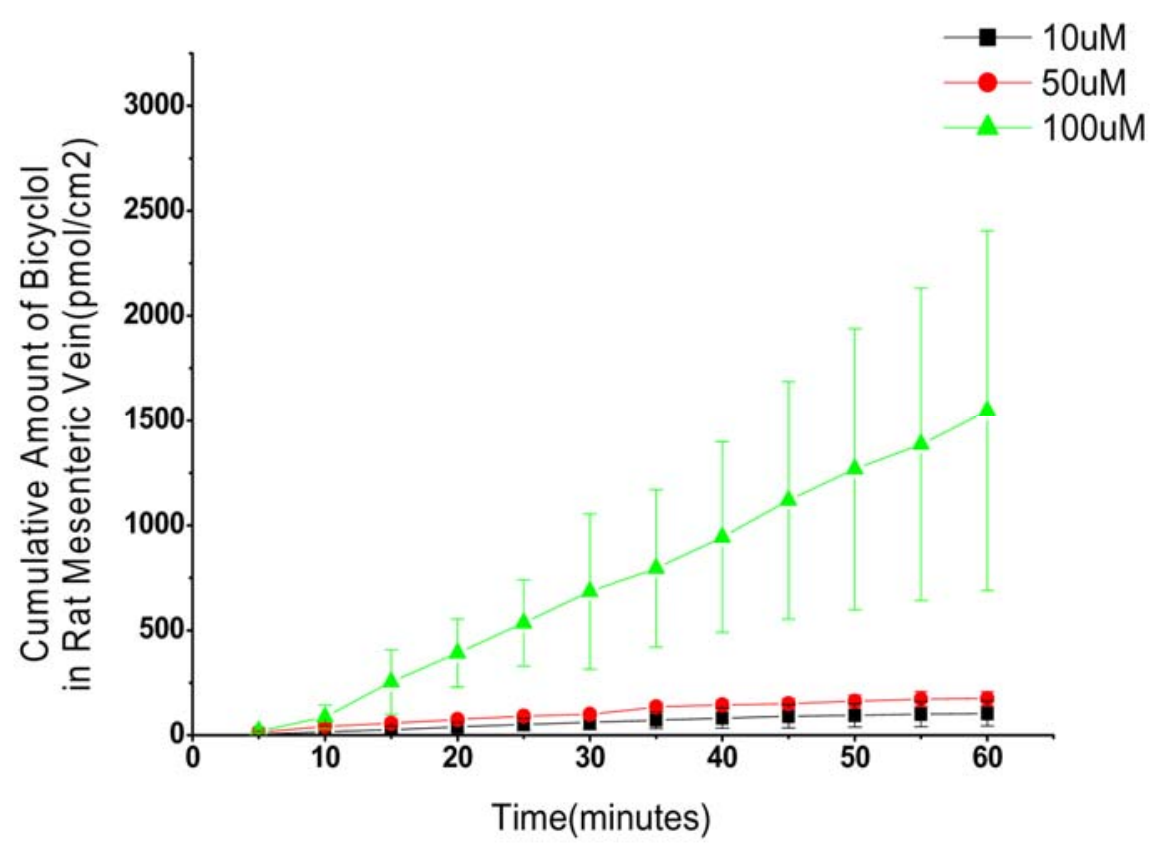

Figure 3. Cumulative amount of bicyclol $(10,50,100 \mu \mathrm{M})$ appearing in mesenteric vein in rat jejunum perfusion study $(n=3)$. Data are expressed as mean \pm SD.

Table 3. Permeabilities and cumulative amount of midazolam in mesenteric vein across rat jejunum.

\begin{tabular}{|c|c|c|}
\hline Condition & $\begin{array}{l}\mathrm{P}_{\text {blood }} \times 10^{-4} \\
(\mathrm{~cm} / \mathrm{s})\end{array}$ & $\begin{array}{c}\text { Cumulative amount of drug in plasma } \\
(\mathrm{pmol} / \mathrm{cm} 2)\end{array}$ \\
\hline $50 \mathrm{uM}$ & $0.05 \pm 0.03$ & $91 \pm 49$ \\
\hline 50uM+5uM LSN335984 & $0.06 \pm 0.03$ & $112 \pm 14$ \\
\hline $50 \mathrm{uM}+20 \mathrm{uM}$ TAO & $0.31 \pm 0.14^{* *}$ & $258 \pm 140^{* *}$ \\
\hline $50 \mathrm{uM}+10 \mathrm{uM}$ CsA & $0.11 \pm 0.05$ & $205 \pm 133$ \\
\hline \multicolumn{3}{|c|}{ 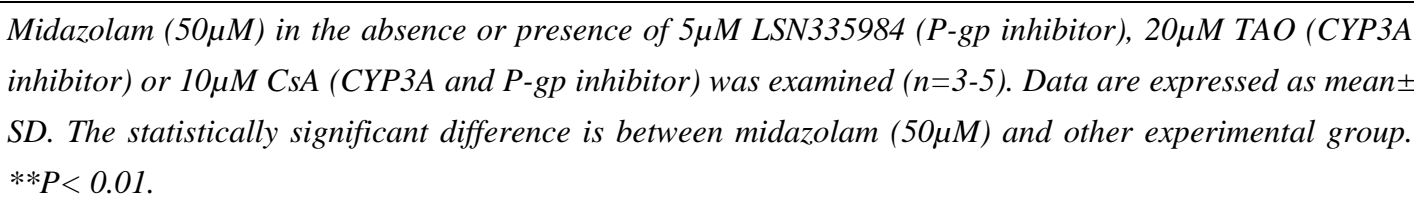 } \\
\hline
\end{tabular}

The ratio (B-A/A-B) of bicyclol in Caco-2 cell was dramatically decreased in the presence of P-gp inhibitor LSN335984 or CsA, indicating that P-gp was involved in the transport of bicyclol in Caco-2 cell. Take together, the results suggested that bicyclol was a well-absorbed compound and P-gp mediated active efflux was likely to be one of reasons for its poor bioavailability.
In addition to P-gp active efflux, extensive metabolism in rat intestine may be another important mechanism responsible for poor bioavailability of bicyclol. For the purpose of observing the co-effect of CYP3A and P-gp in intestine, a suitable concentration of bicyclol was needed to apply to the inhibition study. The 8.2-fold increase in $\mathrm{P}_{\text {blood }}$ of bicyclol with 2-fold 
increase of bicyclol in perfusate $(50 \rightarrow 100 \mu \mathrm{M})$ indicated that P-gp was not effectively pumping the drug back into the intestinal lumen at the 100 $\mu \mathrm{M}$ concentration. In addition, a two-fold increase in the perfusion dose $(50 \rightarrow 100 \mu \mathrm{M})$ resulted in a significant increase ( 8.7 fold) in the appearance of the cumulative amount of bicyclol in mesenteric blood, suggesting that there might be a saturation of intestinal efflux and metabolism of bicyclol at the highest dose. Therefore, a $50 \quad \mu \mathrm{M}$ concentration of bicyclol was chosen in the further studies.

Cummins et al (21) reported that the absorptive permeability of substrate of CYP3A and P-gp in mesenteric vein was increased significantly by GG918 (inhibitor of P-gp), while the permeability of midazolam (substrate of CYP3A only) was unchanged under similar conditions. In addition, another earlier study by Johnson et al showed that the appearance of substrate of CYP3A and P-gp in the mesenteric blood was increased dramatically in the presence of TAO or CsA, compared with control group (18) .In our present study, $\mathrm{P}_{\text {blood }}$ of bicyclol was increased by 3,12 or16-fold in the presence of LSN335984, TAO or CsA, while that of midazolam was almost unchanged with P-gp inhibitor. Moreover, the cumulative amount of bicyclol or midazolam in mesenteric blood showed the same trend as $\mathrm{P}_{\text {blood }}$. Therefore, our results are consistent with previous studies and suggest that bicyclol is a dual substrate of CYP3A and P-gp. Moreover, the significantly higher cumulative amount of bicyclol in blood (3-fold) after addition of TAO, compared with values after LSN335984, indicates that CYP3A related metabolism is more important than P-gp mediated efflux in intestine for the low bioavailability of bicyclol.

In summary, the poor bioavailability of bicyclol is believed to be due to P-gp mediated active efflux and extensive metabolism by CYP3A in rat intestine. Compared with P-gp,
CYP3A related metabolism appears to be more important for the low bioavailability of bicyclol.

\section{ACKNOWLEDGMENTS}

This work was supported by the National Grand Fundamental Research 973 Program of China under Grant No.2004CB518908. We thank Eli Lilly for providing P-gp inhibitor LSN335984. We thank Drs. Carolyn.L.Cummins and Zong Zuo for their helpful comments and suggestion related single-pass perfusion study.

\section{REFERENCES}

[1]. Yao, G.B., Xu, D.Zh., Lan, P., Xu, Ch.B., Wang, Ch., Luo, J., Shen, Y.M., Li, Q., Efficacy and safety of bicyclol in treatment of 2,200 chronic viral hepatitis. Chin J New Drugs Clin Rem, 24:421-426, 2005.

[2]. Liu, G.T., The anti-virus and hepatoprotective effect of bicyclol and its mechanism of action. Clin J New Drug, 10:325-327, 2001.

[3]. Li,Y., Li, Y., Liu, G.T., Protective effects of bicyclol on liver fibrosis induced by carbon tetrachloride. Chin Med J, 84:2096-2101, 2004.

[4]. Wang, H.P., and Li, Y., Protective effect of bicyclol on acute hepatic failure induced by lipopolysaccharide and D-galactosamine in mice. Eur J Pharmacol, 534:194-201, 2006.

[5]. Hu, Q.W., and Liu, G.T., Effects of bicyclol on dimethylnitrosamine-induced liver fibrosis in mice and its mechanism of action. Life Sci, 79:606-612, 2006.

[6]. Ju, M.H., Li, Y., Metabolism of bicyclol in rat and human liver microsomes in vitro. Acta Pharmaceutica Sinica 2005;2:111-116.

[7]. Thummel,K.E., Kunze, K.L., Shen,D.D., Enzyme-catalyzed processes of firstpass hepatic and intestinal drug extraction. Adv Drug Deliv Rev,27:99-127,1997.

[8]. Watkins,P.B., The barrier function of CYP3A4 and P-glycoprotein in the small bowel. Adv Drug Deliv Rev, 27:161-170,1997.

[9]. Benet,L.Z., Cummins,C.L., The drug efflux-metabolism alliance: biochemical aspects. Adv Drug Deliv 
Rev,50:S3-S11,2001.

[10]. Johnson, B.M., Charman, W.N., Porter,C.J.H., The impact of P-glycoprotein efflux on enterocyte residence time and enterocyte-based metabolism of verapamil. J Pharm Pharmacol,53:1611-1619, 2001.

[11]. Cummins,C.L., Jacobsen, W., Benet, L.Z., Unmasking the Dynamic Interplay between Intestinal P-Glycoprotein and CYP3A4. J Pharmacol Exp Ther, 300:1036-1045, 2002.

[12]. De, Waziers., Cugnenc,P.H., Yang,C.S., Leroux, J.P., Beaune,P.H., Cytochrome P450 isoenzymes, epoxide hydrolase and glutathione transferases in rat and human hepatic and extrahepatic tissues. J Pharmacol Exp Ther, 253:387-394,1990.

[13]. Kolars, J.C., Lown, K.S., Schmiedlin, R.P., Ghosh, M., Fang, C., Wrighton, S.A., Merion, R.M., Watkins,P.B., CYP3A gene expression in human gut epithelium. Pharmacogenetics,4:247-259, 1994.

[14]. Wacher, V.J., Silverman, J.A., Zhang, Y., Benet, L.Z., Role of P-glycoprotein and cytochrome $\mathrm{P} 4503 \mathrm{~A}$ in limiting oral absorption of peptides and peptidomimetics. J Pharm Sci, 87:1322-1330, 1998.

[15]. Liu, Z,Q, Jiang, Z.H., Liu,L., Hu, M., Mechanisms responsible for poor oral bioavailability of paeoniflorin: role of intestinal disposition and interactions with sinomenine. Pharm Res, 12:2768-2780, 2006.

[16]. Hu,M., Chen, J., Tran,D., Zhu,Y., Leonardo,G., The Caco-2 cell monolayers as an intestinal metabolism model: metabolism of dipeptide Phe-Pro. J.Drug.Target,2:79-89, 1994.

[17]. Hu, M., Chen,J., Zhu,Y., Dantzig, AH., Stratford,J.R., Kuhfeld,M.T. Mechanism and kinetics of transcellular transport of a new $\beta$-lactam antibiotic loracarbef across an human intestinal epithelial model system (Caco-2). Pharm Res (NY),11:1405-1413, 1994.

[18]. Johnson,B.M., Chen,W.Q., Borchardt,R.T.,
Charman,W.N., Porter,C.J.H., A kinetic evaluation of the absorption, efflux, and metabolism of verapamil in the autoperfused rat jejunum. $\mathrm{J}$ Pharmacol Exp Ther 305:151-158, 2003.

[19]. Singhal,D., Ho,NF., Anderson,B.D., Absorption and intestinal metabolism of purine dideoxynucleosides and an adenosine deaminase-activated prodrug of 2',3'-dideoxyinosine in the mesenteric vein cannulated rat ileum. J Pharm Sci, 87:569-577, 1998.

[20]. Artursson,P.,and Karlsson,J.. Correlation between oral drug absorption in humans and apparent drug permeability coefficients in human intestinal epithelial (Caco-2) cells. Biochem Biophys Res Commun, 175:880-885, 1991.

[21]. Yee,S., In vitro permeability across Caco-2 cells (colonic) can predict in vivo (small intestinal) absorption in manVfact or myth. Pharm Res, 14:763-766, 1997.

[22]. Cummins,C.L., Salphati,L., Reid,M.J., Benet,L.Z., In Vivo Modulation of Intestinal CYP3A Metabolism by P-Glycoprotein: Studies Using the Rat Single-Pass Intestinal Perfusion Model. J Pharmacol Exp Ther,305:306-314,2003.

[23]. Zhang,L., Lin,G., Chang,Q., Zuo,Z., Role of intestinal first-pass metabolism of baicalein in its absorption process. Pharm Res, 7:1050-1058,2005.

[24]. Jeong,E.J., Liu,Y., Lin,H., Hu,M.,In situ single-pass perfused rat intestinal model for absorption and metabolism. In Z. Yan and G. W. Caldwell (eds.), In Methods in Pharmacology and Toxicology: Optimization in Drug Discovery-In Vitro Methods, Human, Totowa, NJ, pp. 65-76, 2004.

[25]. Wang,Y., Aun,R., Tse,F.L.,1 Absorption of D-glucose in the rat studied using in situ intestinal perfusion: a permeability-index approach. Pharm Res,14:1563-1567, 1997. 